\title{
Mobilizing Subjectivity: An Interview with Victoria Marks
}

\author{
Harmony Bench, The Ohio State University \\ Victoria Marks, University of California, Los Angeles
}

Harmony Bench-The theme for this particular issue of The International Journal of Screendance is community, and when we were discussing this idea as an editorial board, your work came immediately to mind because I think this has been a constant refrain in the works you've made both for screen and stage. I think our readers will be familiar with your work with Margaret Williams from the 1990s-Outside In, Mothers and Daughters, and Men are quite canonical-but they might be less familiar with your more recent film Veterans and your work with what you call Action Conversations. I'm hoping that you could reflect just briefly on those earlier works to think through the questions you were asking with those pieces, and how those questions have either shifted or remained the same in your more recent work.

Victoria Marks-My work took a major shift when I worked with Candoco and Margaret Williams on Outside In. I think there were a few conditions that led to that change, and those were that I was making a 13 minute film for broadcast, and that I was working with an "integrated dance company," a group of dancers who were physically disabled and non-disabled. The opportunity, I felt I had, was to change the way disability is thought about in 13 minutes. Now, I know that's absurd, but it's also a great call to what choreography could do. Going into the project, I didn't say "okay, here's what I want to make a piece about," or "here's a movement idea I want to explore," as much as to say "please teach me the issues for your community," and then to work with those ideas in as poetic and compelling a way as possible using choreography as a medium. I say that because I think one could walk in with a very didactic approach to representation-"this is how I want to be represented, so let's concretely do that." I think I really wanted to look at it as a choreographic and cinematic enterprise-and Margaret also. But because of that piece, I began to think that there was a way to enter into making things that wasn't so much about "Here's the idea that I have," as much as to say "Let me listen very carefully and think about the ways in which you are interacting and the ways in which you wish to be represented, set alongside the ways in which I see you." So, not necessarily consciously, that changed a great deal of my work, which I started calling choreo-portraiture.

Mothers and Daughters and Men followed quickly after Outside In. Mothers and Daughters actually was a portrait of the main dancers Anna and her mother Marta, and

The International Journal of Screendance 5 (2015). 
everyone else was sort of a chorus. But I was also informed by my own relationship with my mother, so it was very clear to me that while I was making a portrait, it was never independent of my own experience. I was very aware of the ways I was seeing into that relationship. With Men, similarly, I think it was informed by observations about my dad getting old. But as soon as I started working with the men, I realized they weren't my dad. So it became about them, but it was always informed by a younger woman looking at older men. So that was my framework that began my thinking about portraiture. And by no means am I confused, thinking that these are actual portraits, because there may be a lot of friction between the subjects who are "portraitized" and the maker of the portrait.

HB-So do you feel that some of these same issues arise in Veterans or in your Action Conversations, or does a completely different set of questions arise? Is Veterans also a choreo-portrait?

VM-No, not really. The reason why Action Conversations came about-which, in its purest form in my mind, is when I bring two groups of people into a room that would not otherwise be in that room together, to see what happens, like a petri dish. In the sense of portraiture, I impact that Action Conversation because of the atmosphere I create, because of the questions I ask, because of the exercises we begin with. So I impose myself in that way, but in a much less mediated way than in Men, and Outside In, and Mothers and Daughters, where I felt like I was really imposing "compassionate aesthetics" or something on my subjects. But with Action Conversations, I was interested in the chemistry between the groups of people in the room, and I wanted that to formulate the material in a much more direct way.

HB-Could you explain a little bit more about what an Action Conversation is, and what kinds of questions you might ask in that process?

VM-The conception of the Action Conversation came about because I wanted to respond to the War in Iraq. In 2003, the U.S. invaded Iraq, Bush was President, and I had two 3-year old boys. I wanted to know what it would be like to be a good citizen with the skills that I have, which are choreographic. So I launched a variety of different projects at that time in relationship to the invasion of Iraq. I didn't have anyone in my family in the military, and I wanted to connect with actual people who were in military service. Prior to that time, I had been working and thinking about the representation of disability, and I thought there was an interesting opportunity for me to expand my thinking about disability if I could meet people who had served in the military. I immediately became tuned into the issues around Post Traumatic Stress Disorder. Where I had been thinking about disability as in physical disabilities, I began for the first time to think about the ways in which a dance might represent individuals with invisible 


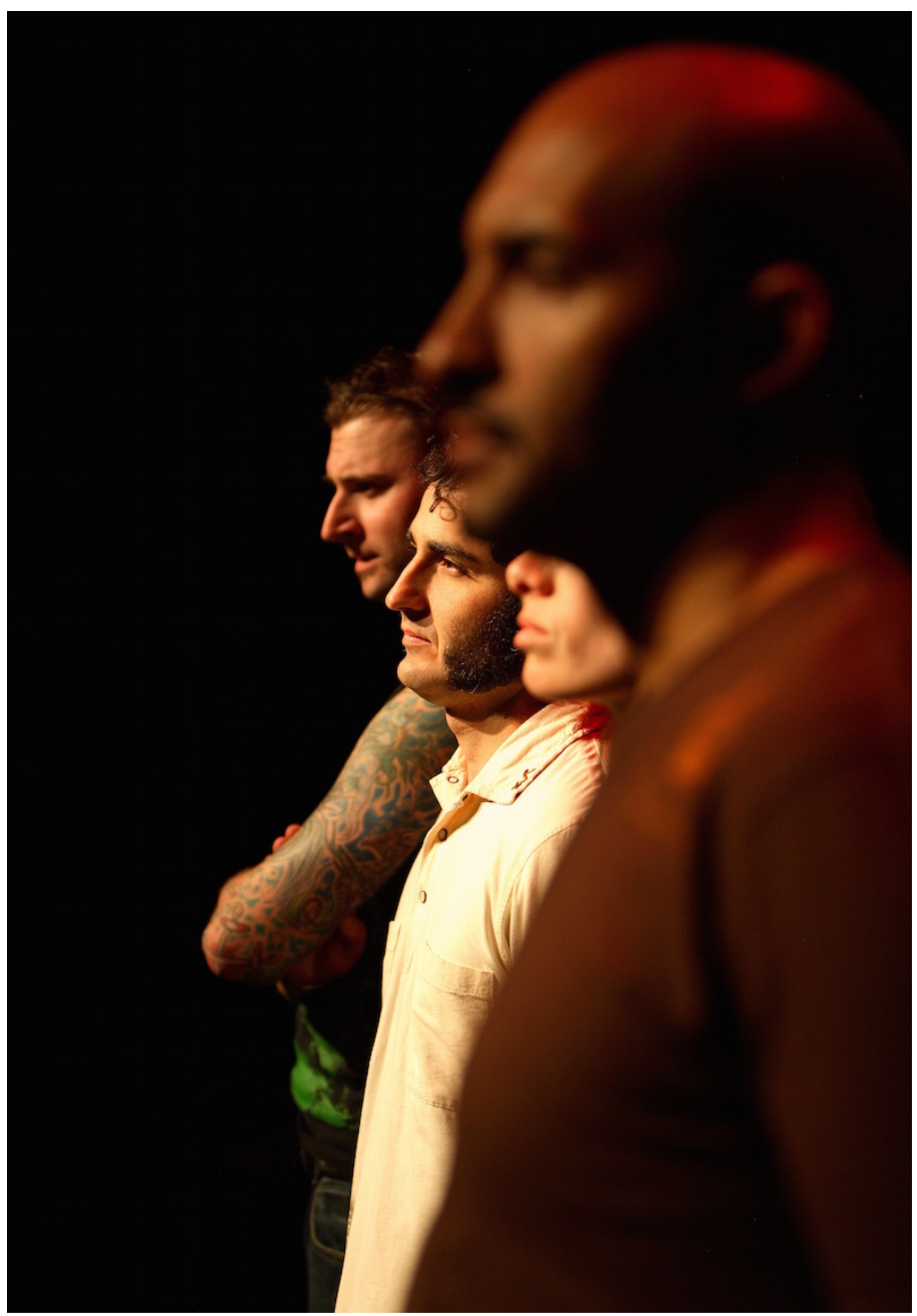

Veterans in Action Conversations. Performers from left to right: Aaron McCollum, Manuel Flores, Eva Aymami, Cidkyee Williams. Photo by Rose Eichenbaum, courtesy Victoria Marks. Highways Performance Space, Santa Monica, CA, 2008. 
disabilities. And then I also realized that there are enormous ethical concerns: what right do I have to walk into a room and tell a bunch of guys who had just come back from serving in the military what to do, or ask them questions, or play any role in their lives? So before Action Conversations even began I was talking to veterans, I met a doctor at the West Los Angeles Veteran's Administration hospital who I spoke to about my interests, and gradually, I came up with the idea because of those conversations to create-I mean, I couldn't talk about what I was doing as dance-so I came up with the idea of an Action Conversation, and I would bring other people into the room who in some ways would be a surrogate for me in a conversation. So in this case it was a group of grad students and associated artists in LA. Honestly, it took so long for it to even begin because I didn't have the connections. And gradually, the connections got made through the internet, through Craigslist. "Some wacky professor at UCLA wants to do this project with veterans," you know, and, actually, that's how it happened. But it took a long time to circulate and go that far, because I was just reaching out everywhere I could.

I think it's important for me that the Action Conversation structure was a response to wanting to enter into a conversation that I didn't know how to have. And I thought that if I brought a second group of people into the room who would also be interested in the conversation, they would, in a sense, be surrogates for me, and I could compose the interactions between veterans and, in this case, artists/grad students.

And I noticed that as a "dance person," or as a "teacher person," if you go into a studio and set up an improvisation exercise for dancers, after some substantial explorations within that exercise, it is conventional to sit down and talk about the experience. And when you work with dancers doing that, very often, their attention goes to elements of their practice, whether it's "this was challenging for me," or, "I noticed that this was a possibility that I hadn't noticed before," but mostly dancers' responses would be about dancing. But I noticed that if I do that with a group of people who are not dancers, their responses, when asked "what was interesting, or what happened, or what was challenging," their responses would always be about their relationships; about themselves.

$\mathrm{HB}$-Their relationships to each other in the studio, or their relationships outside of that space?

VM-Both. So for example, if I was doing an improvisational exercise, that explored falling and catching-let's say the instructions are that you have to run to somebody who falls as they say "FALLING!" the discussion afterwards with the veterans was, "Oh my gosh! I just felt that if I didn't get to Aaron on time, it would be a disaster, and this kind of makes my adrenaline pump, because I was a first responder, and I just felt that it was my job to catch people when they were falling." So it moved very quickly into metaphor, and catalyzed the kinds of conversations that I wouldn't have imagined. I 
started using that afterwards to turn the discussion into a metaphorical physical exercise. So it would progress. So for example, if I was a first responder, then somebody could say "Help" when they fall, and if you don't make it in time, we could consider an option for what you can do if you don't catch somebody. So I would take them down whatever road they were collectively or individually thinking about. The challenge is for it not to turn into a kind of interactional psychology project, but to build relationships. I felt like in any conversation, the project that's lying there waiting is to build relationships across very different experiences. And sometimes those are about our commonalities, but most often it's about actually acknowledging how different the people are in the room, and the ways in which they can still come together. ${ }^{1}$

HB-You mentioned the importance of listening to the people who are in the room and the communities that they are coming from. Has this Action Conversation modality emerged as a method, or as a way of listening? Has it become a codified approach, or a collection of resources that allow you to listen in a certain way when you go into these communities?

VM-I don't think it's either, and I kind of think it's both. People started thinking, "Oh, Vic is really interested in doing this work with vets," and while I was very moved by that work, and we sustained a few years of projects together, I realized that that wasn't my calling, to work on veteran issues, as much as to continue to find ways to use dance to make different kinds of poetries. And I wanted to know more about Action Conversations, so I wanted to test it out on different communities. And that's where I think it's a methodology, but it's completely different with each group. The next time I worked with Action Conversations was in Vermont in Bellows Falls under the auspices of Vermont Performance Lab. Sara Coffey asked, "What would you like to do?" and I said, "I would like to see if I could be involved in a civic conversation-something that matters to a town. I think it was partly in response to not knowing how to be in Los Angeles, and thinking if I could just work small, and think about how we are all working together in our different roles, that would be something to learn from. So in Bellows Falls, there's a concern for young women who are getting pregnant in their teens and dropping out of school, and there's multi-generational poverty in these old mill towns, so in conversation with Sara Coffey, we created an Action Conversation between a group of these young women, teens, and older women from the same community. I felt like, while the veterans were a vulnerable population, they were also excited about the opportunity to perform live, and we were all in LA. But with these young women, I felt like they would be too vulnerable and it would be too complicated for them to perform live in their own community, or anywhere else, so we chose to document the project with video. I worked with the filmmaker Ann Kaneko, and in my mind, I thought that somehow we were going to land somewhere between a dance for the camera and a documentary. I didn't really know how, but I thought maybe we could create a hybrid, documentary and choreographic cinema, because I thought process was importantwe really needed to know who these people were, and at the same time, I wanted to 
use choreography to create images that supported what was going on. So it was different-it began with two groups of people that didn't know each other. ${ }^{2}$

Right now I've just started working with sorority women, which is really interesting. I can't call it an Action Conversation because I only have sorority women from a couple of different houses. But in the spring I'll bring fraternity men and sorority women together for an Action Conversation, where we will address sexual violence. In this case, an Action Conversation will be set up with an agenda beyond just the people in the room. I hope to use it in some way in between mediation, opening up conversation, and artmaking together.

I realize that what is consistent in all this work is an interest in mobilizing subjectivity through dancing-especially for under-represented groups.

There have been various historic controversies between "high art" and "community art." Especially spending time in England, I noted that these were very different streams. I don't know the full history of community work versus "high art," but I want to resist the idea that my art is therapy, even though sometimes it's interpreted as "oh, that was so healing, why don't you do it with this population over here?" I want to resist that its purpose is for community-building alone, because I try to experiment with my medium, and hold to the poetics of who is in room and how it happens, or new syntaxes. I'm trying to resist the drop-down into "providing services."

HB-When you look at your work, what stands out for you?

VM-What comes across to me is the hard and generous work of the people who were involved. I guess it's like I'm in love with each of them. It's that sense of subjectivity, that sense of "Look what happened when we just came together."

\section{Biography}

Victoria Marks, an Alpert Award winner (1997) and Guggenheim Fellow (2005), has been practicing knowing and unknowing, making dances for stage and film, over the past 27 years. Marks' creative work migrates between choreo-portraits for individuals who don't identify as dancers-and dances for and with dancers that fuel Marks' inquiries into movement. Her current "Action Conversations" project, designed to bring two groups into productive dialogue through movement, is working with Greek college students addressing "Desire on Campus." Marks is a Professor of Choreography in the Department of World Arts and Cultures/Dance at UCLA, where she has been teaching since 1995. 
Marks has received numerous grants and fellowships, including from the Irvine Foundation, National Endowment for the Arts, Los Angeles City Department of Cultural Affairs, New York State Council on the Arts, New York Foundation for the Arts, and the London Arts Board, among others. She has received a Fulbright Fellowship in Choreography, and numerous awards for her dance films co-created with Margaret Williams, including the Grand Prix in the Video Danse Festival (1996 and 1995), the Golden Antenae Award from Bulgaria, the IMZ Award for best screen choreography and the Best of Show in the Dance Film Association's Dance and the Camera Festival.

For more information on Victoria Marks's work, including her published essays, go to www.victoriamarks.com

\section{Notes}

${ }^{1}$ See Action Conversations: Veterans. The password for the Vimeo video is "vets." https://vimeo.com/album/2916653/video/99743786

${ }^{2}$ See a clip from Action Conversations: Bellows Falls at

http://vermontperformancelab.org/video4/190-victoria-marks-ann-kaneko

\section{References}

Action Conversations: Bellows Falls. Dir. Ann Kaneko. Chor. Victoria Marks. Prod. Vermont Performance Lab. 2012. DVD.

Action Conversations: Veterans. Dir. (film) Ann Kaneko. Chor. and dir. (performance) Victoria Marks. 2005. DVD.

Men. Dir. Margaret Williams. Chor. Victoria Marks. Comp. Andy Teirstein. Prod. MJW Productions. 1997. Television.

Mothers and Daughters. Dir. Margaret Williams. Chor. Victoria Marks. Comp. John Middlewick. Prod. MJW Productions. 1996. Television.

Outside In. Dir. Margaret Williams. Chor. Victoria Marks. Perf. Candoco Dance Company. Comp. Steve Beresford. Prod. MJW Productions. 1995. Television.

Veterans. Dir. Margaret Williams. Chor. Victoria Marks. Prod. EMPAC. 2008. DVD. 